\title{
Book review on The Geopolitics of Energy
}

\author{
Michael Narodoslawsky
}

\section{Book details}

Favennec, JP

The Geopolitics of Energy

Paris: Editions Technip; 2011

312 pages, ISBN 978-2-7108-0970-8

Energy permeates all aspects of the economy. Prices and availability of energy in its different forms are major factors that structure the economy as well as the way of life of societies. Therefore, energy is an important issue of geopolitics, creating dependencies and conflicts between nations and increasingly becoming a topic in the international political arena.

In his book, The Geopolitics of Energy, Jean-Pierre Favennec provides a comprehensive overview of the different strategic aspects of energy, energy markets and the development of energy issues in light of geopolitics. The book explains the ascent of energy as an ever more important political and strategic factor from a historical point of market development as well as the development and motivation of key actors in the field of energy, from governments to national and international companies as well as supra-national players such as OPEC. Besides these general insights into the role and function of major stakeholders in the global energy system, the book offers a detailed view on the political dimension of energy in different global regions.

Jean-Pierre Favennec's book captivates the reader with its richness in profound knowledge about the strategic role of energy in today's global political system. It also provides a treasure of interesting data about energy, the energy markets, the energy supply security and the flow of energy in the global economy. In particular, the book provides a very detailed view of the energy systems within global regions with regard to the stakeholders, their mutual dependency, their role and political weight as well as the challenges and chances that these regions face in the future. It is this part of the book that provides the most interesting data and insights into the strategic importance of energy as a formative factor for policy, economy and society.

There are many interesting aspects of this encompassing treatise of the geopolitical impact of energy. One of the most enthralling issues dealt with in the book is the role of national and international energy companies. The book does not only provide important data on their impact on the international energy system, but also reveals their motivation as well as their structural interaction with other stakeholders, from national governments to non-governmental organisations. A particular strength of Jean-Pierre Favennec's book is that these interactions are not only investigated on a global and historical scale, but also on a detailed region-by-region and, in many cases, state-by-state levels.

The Geopolitics of Energy is a solid and encompassing source of knowledge about the strategic role and importance of energy which is essential reading for all who are truly interested in researching as well as shaping energy issues. Despite a somewhat bumpy translation from French, the book in its English version is captivating and a source of broad as well as deep knowledge and detailed, well-researched data that are clearly represented and exhaustingly explained. The book is strongly recommended to all energy experts as well as researchers and, in particular, lecturers as it provides a profound knowledge in the intricacy of political, economic and social impact of energy supply and exploitation.

\section{Competing interests \\ The author declares that he has no competing interests.}

\section{Author's information}

$\mathrm{MN}$ is the Editor-in-Chief of Energy, Sustainability and Society. His research and teaching are dedicated to sustainable process engineering, ecological process evaluation and regional sustainable energy systems.

Received: 9 January 2013 Accepted: 13 January 2013

Published: 29 January 2013 